\title{
Predictors of abnormal brain computed tomography findings in patients with acute altered mental status in the emergency department
}

\author{
Somi Shin, Hui Jai Lee, Jongwhan Shin, Sejong Lee \\ Department Emergency Medicine, Seoul Metropolitan Government-Seoul National University Boramae \\ Medical Center, Seoul, Korea
}

Objective Brain computed tomography (CT) is commonly performed to diagnose acute altered mental status (AMS), a critically important symptom in many serious diseases. However, negative CT results are common, which result in unnecessary CT use. Therefore, this study aimed to determine the clinical factors associated with positive CT findings.

Methods Patients with acute AMS selected from an emergency department-based registry were retrospectively evaluated. Patients with non-traumatic and noncommunicable diseases on initial presentation and with Glasgow Comal Scale scores of $<15$ were included in the study.

Results Among the 367 brain CT results of patients with AMS during the study period, 146 (39.8\%) were positive. In a multivariate analysis, the presence of focal neurologic deficit (odds ratio [OR], 132.6; 95\% confidence interval [Cl], 37.8 to 464.6), C-reactive protein level $<2 \mathrm{mg} / \mathrm{dL}(\mathrm{OR}, 3.9$; $95 \% \mathrm{Cl}, 1.4$ to 10.6), and Glasgow Comal Scale score $<9(\mathrm{OR}, 2.4 ; 95 \% \mathrm{Cl}, 1.2$ to 4.8$)$ were significantly associated with positive brain $\mathrm{CT}$ results.

Conclusion The presence of focal neurologic deficit, initial Glasgow Comal Scale score of $<9$, and initial C-reactive protein levels of $<2 \mathrm{mg} / \mathrm{dL}$ can facilitate the selection of brain $\mathrm{CT}$ to diagnose patients with acute AMS in the emergency department.

Keywords Unconsciousness; Tomography, X-Ray computed; Diagnosis; Risk factors

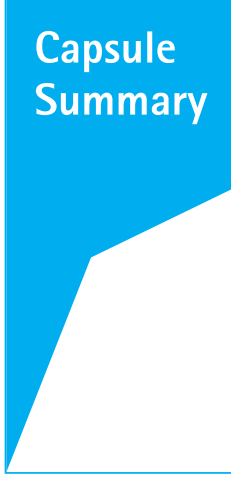

What is already known

Brain computed tomography (CT) is a primary diagnostic approach in patients with acute altered mental status. However, recent studies revealed high rates of negative brain CT findings and issues associated with unnecessary radiation exposure.

What is new in the current study

Considering the neurologic examination findings (presence of focal neurologic deficit and Glasgow Coma Scale) and C-reactive protein results, unnecessary use of brain CT can be reduced.
elSSN: 2383-4625

Received: 15 July 2017

Revised: 17 October 2017

Accepted: 24 October 2017

Correspondence to: Hui Jai Lee Department Emergency Medicine, Seoul Metropolitan Government-Seoul National University Boramae Medical Center, 20 Boramae-ro 5-gil, Dongjakgu, Seoul 07061, Korea

E-mail: emdrlee@snu.ac.kr

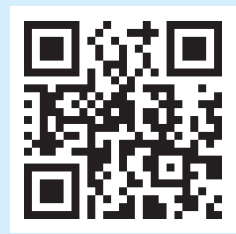

How to cite this article:

Shin S, Lee HJ, Shin J, Lee S. Predictors of abnormal brain computed tomography findings in patients with acute altered mental status in the emergency department. Clin Exp Emerg Med 2018;5(1):1-6.

This is an Open Access article distributed under the terms of the Creative Commons Attribution Non-Commercial License (http:// creativecommons.org/licenses/by-nc/4.0/). 


\section{INTRODUCTION}

Altered mental status (AMS) is one of the most common chief complaints reported in 4\% to 10\% of emergency department (ED) patients..$^{1-3} \mathrm{~A}$ wide range of clinical conditions can cause acute AMS, either direct central nervous system (CNS) pathologies such as stroke, seizure, and encephalitis or non-CNS-origin such as sepsis, metabolic imbalance, cardiogenic shock, and intoxication. Moreover, history taking in patients with AMS is, due to their condition, problematic. Thus, determining the exact etiology in patients with AMS is challenging for emergency physicians. ${ }^{1,3}$

Brain computed tomography (CT), the primary diagnostic tool to identify intracranial pathologies, has been recommended for AMS. ${ }^{1,3,4}$ Unfortunately, brain CT has some limitations when used to diagnose non-intracranial pathology-related AMS. ${ }^{2,5,6}$

Studies evaluating the brain $\mathrm{CT}$ of patients with AMS without trauma were limited, as most previous studies investigated its effectiveness in patients with traumatic brain injuries. Therefore, this study aimed to evaluate the effectiveness of brain CT in patients with non-traumatic AMS and, consequently, determine the clinical characteristics predictive of positive brain CT findings in these patients.

\section{METHODS}

\section{Study setting}

This study was conducted at a single urban academic hospital with an annual ED census of 55,000. A retrospective ED-based registry of AMS was reviewed from April to December 2014. Nontrauma patients who had Glasgow Coma Scale (GCS) scores of $\leq 14$ and presented to the ED with noncommunicable disease were enrolled in this study. Those who had previous neurologic deficit (modified Rankin Scale of $\geq 2$ ), uncomplicated ethanol ingestion, cardiac arrest, aged $<18$ years, or recovered from mental illness at the time of the initial ED evaluation were excluded.

Basic patient characteristics such as age, sex, medical history and previous medications, initial vital signs, neurologic findings, initial laboratory test results, brain CT findings, and final diagnoses were collected. One senior resident (third or fourth year) or faculty of emergency medicine performed full neurologic exams in the patients to determine any cranial nerve abnormality, motor weakness, or cerebellar dysfunction. Only brain CT results conducted in the ED were included for evaluation. Brain CT findings, formal reports, and final diagnoses were reviewed by a faculty of emergency medicine. "Positive CT finding" was defined as the presence of abnormal findings suggestive of acute AMS. This study was approved by the institutional review board of the study hospital (16-2015-3), and written informed consents were waived.
Table 1. Clinical characteristics of patients with acute mental changes

\begin{tabular}{|c|c|c|c|}
\hline \multirow{2}{*}{ Characteristics } & \multicolumn{2}{|c|}{ Brain CT } & \multirow{2}{*}{ P-value } \\
\hline & Done $(n=367)$ & Not done $(n=141)$ & \\
\hline Age (yr) & $66.32 \pm 15.27$ & $63.27 \pm 18.21$ & 0.079 \\
\hline Male & $195(52.0)$ & $66(46.8)$ & \\
\hline Current-smoker & 71 (19.3) & 17 (16.3) & 0.317 \\
\hline Frequent alcohol drinking ${ }^{\text {a) }}$ & $35(9.5)$ & 8 (8.2) & 0.273 \\
\hline Glasgow Coma Scale & $8.45 \pm 3.37$ & $9.47 \pm 3.50$ & 0.002 \\
\hline Mental status & & & 0.006 \\
\hline Confusion & $0(0)$ & $1(0.7)$ & \\
\hline Lethargy & $223(60.8)$ & $104(73.8)$ & \\
\hline Stupor & $66(18.0)$ & $15(10.6)$ & \\
\hline Semicoma & $42(11.4)$ & $6(4.3)$ & \\
\hline Coma & $36(9.8)$ & $15(10.6)$ & \\
\hline \multicolumn{4}{|l|}{ Underlying conditions } \\
\hline Hypertension & $166(45.2)$ & $64(45.4)$ & 0.981 \\
\hline Diabetes mellitus & $110(30.0)$ & $59(41.8)$ & 0.015 \\
\hline Malignancy & $45(12.3)$ & $22(15.6)$ & 0.342 \\
\hline Chronic liver disease & $35(9.5)$ & $15(10.6)$ & 0.709 \\
\hline Chronic kidney disease & $26(7.1)$ & $13(9.2)$ & 0.418 \\
\hline Cerebrovascular disease & $92(25.1)$ & $23(16.3)$ & 0.029 \\
\hline Parkinson's disease & $8(2.2)$ & $4(2.8)$ & 0.746 \\
\hline Dementia & $42(11.4)$ & $16(11.3)$ & $>0.990$ \\
\hline \multicolumn{4}{|l|}{ Medication } \\
\hline Psychotropic & $39(10.6)$ & $24(17.0)$ & 0.050 \\
\hline Anticonvulsant & $21(5.7)$ & $12(8.51)$ & 0.270 \\
\hline Cardiovascular & 177 (48.2) & $68(48.2)$ & 0.861 \\
\hline Opioid & $6(1.6)$ & $5(3.5)$ & 0.192 \\
\hline $\begin{array}{l}\text { Medications for chronic } \\
\text { neurologic disorder }\end{array}$ & $25(6.8)$ & $9(6.8)$ & 0.892 \\
\hline \multicolumn{4}{|l|}{ Initial vital signs } \\
\hline $\mathrm{SBP}(\mathrm{mmHg})$ & $111.67 \pm 63.78$ & $93.72 \pm 61.37$ & 0.004 \\
\hline $\mathrm{DBP}(\mathrm{mmHg})$ & $62.90 \pm 34.76$ & $54.67 \pm 3.95$ & 0.016 \\
\hline Heart rate $(/ \mathrm{min})$ & $88.58 \pm 23.97$ & $91.96 \pm 22.14$ & 0.214 \\
\hline Respiratory rate (/min) & $16.68 \pm 8.39$ & $15.66 \pm 10.37$ & 0.299 \\
\hline Body temperature $\left({ }^{\circ} \mathrm{C}\right)$ & $36.55 \pm 1.03$ & $36.51 \pm 1.04$ & 0.106 \\
\hline \multicolumn{4}{|l|}{ Laboratory results } \\
\hline WBC $\left(10^{3} / \mu \mathrm{L}\right)$ & $11.34 \pm 8.43$ & $11.79 \pm 10.34$ & 0.707 \\
\hline Hemoglobin $(\mathrm{g} / \mathrm{dL})$ & $12.76 \pm 2.62$ & $12.23 \pm 2.73$ & 0.045 \\
\hline Sodium (mM/L) & $137.3 \pm 6.18$ & $135.9 \pm 7.43$ & 0.031 \\
\hline Potassium (mM/L) & $4.10 \pm 0.84$ & $4.25 \pm 1.09$ & 0.150 \\
\hline BUN (mg/dL) & $25.96 \pm 21.26$ & $26.97 \pm 20.46$ & 0.629 \\
\hline Creatinine (mg/dL) & $1.82 \pm 7.65$ & $1.58 \pm 1.65$ & 0.717 \\
\hline Glucose (mg/dL) & $174.74 \pm 127.03$ & $170.97 \pm 151.20$ & 0.778 \\
\hline AST (IU/L) & $67.82 \pm 170.79$ & $82.89 \pm 269.83$ & 0.454 \\
\hline ALT (IU/L) & $31.55 \pm 71.73$ & $36.05 \pm 79.17$ & 0.539 \\
\hline Total bilirubin (mg/dL) & $1.48 \pm 2.24$ & $1.54 \pm 2.39$ & 0.781 \\
\hline Albumin $(\mathrm{g} / \mathrm{dL})$ & $3.83 \pm 2.13$ & $3.60 \pm 0.63$ & 0.212 \\
\hline Creatine kinase (U/L) & $353.02 \pm 772.33$ & $347.09 \pm 704.58$ & 0.945 \\
\hline C-reactive protein $(\mathrm{mg} / \mathrm{dL})$ & $3.21 \pm 6.86$ & $4.55 \pm 8.53$ & 0.098 \\
\hline \multicolumn{4}{|l|}{ Neurologic exam } \\
\hline Focal neurologic deficit ${ }^{b)}$ & $90(26.3)$ & $1(0.7)$ & $<0.001$ \\
\hline Cranial nerve abnormality & 49 (13.4) & $1(0.7)$ & $<0.001$ \\
\hline Extremity abnormality & $78(21.3)$ & $1(0.7)$ & $<0.001$ \\
\hline Cerebellar abnormality & $1(0.3)$ & $0(0)$ & $>0.990$ \\
\hline
\end{tabular}

Values are presented as mean \pm standard deviation or number (\%).

$\mathrm{CT}$, computed tomography; SBP, systolic blood pressure; DBP, diastolic blood pressure; WBC, white blood cell; BUN, blood urea nitrogen; AST, aspartate aminotransferase; ALT, alanine aminotransferase.

a) $>4$ days per week. ${ }^{\text {b) }}$ Cranial nerve, extremity, and cerebellar abnormality. 


\section{Statistical analysis}

Statistical analyses were performed using the IBM SPSS Statistics ver. 20 (IBM Corp., Armonk, NY, USA) and R ver. 3.3.1 (R Foundation for Statistical Computing, Vienna, Austria). Categorical variables were recorded as frequency with the corresponding percentage and compared using the chi-square or Fisher's exact test as appropriate. Continuous variables were expressed as the mean \pm standard deviation, and Student t-tests were performed. Multivariate logistic models were performed using the forward selection approach, and the results were recorded as adjusted odds ratio (OR) with 95\% confidence interval (CI). Conditional Inference Tree Analysis was performed to generate a decision tree to predict positive brain CT results using the R package "Party" ver. 1.0$25 .{ }^{7.8}$ All statistical tests were two-tailed at 0.05 level of significance.

\section{RESULTS}

A total of 508 patients treated during the study period met the eligibility criteria and were enrolled in the registry. Among them, 367 (72.2\%) patients had undergone brain CT in the ED. All patients with a focal neurologic deficit underwent brain CT, except one who underwent brain magnetic resonance imaging. Table 1 presents the baseline characteristics of the patients.

A total of 146 patients had positive CT findings: 81 (55.5\%) had intracranial hemorrhage, 54 (37.0\%) infarction, 10 (6.8\%) tumor, and $1(0.7 \%)$ brain swelling. The most common cause was cerebrovascular etiology $(122,83.6 \%)$ (Table 2). Table 3 shows the clinical parameters according to brain CT results.

Table 2. Etiologies of acute altered mental status in each group

\begin{tabular}{lcc}
\hline Etiology & CT negative & CT positive \\
\hline Cerebrovascular & $5(2.3)$ & $122(83.6)$ \\
CNS infection & $4(1.8)$ & $2(1.4)$ \\
CNS tumor & $1(0.5)$ & $5(3.4)$ \\
Seizure/postictal confusion & $29(13.1)$ & $6(4.1)$ \\
Other CNS pathology & $4(1.8)$ & $1(0.7)$ \\
Sepsis & $27(12.2)$ & $5(3.4)$ \\
Hepatic encephalopathy & $24(10.9)$ & $1(0.7)$ \\
Hypoglycemia & $18(8.1)$ & $0(0)$ \\
Other metabolic derangement & $32(14.5)$ & $2(1.4)$ \\
Cardiovascular & $10(4.5)$ & $0(0)$ \\
Hypoxia & $6(2.7)$ & $1(0.7)$ \\
Drug intoxication & $43(19.5)$ & $1(0.7)$ \\
Psychiatric & $6(2.7)$ & $0(0)$ \\
Environmental injury & $10(4.5)$ & $0(0)$ \\
Unknown & $2(0.9)$ & $0(0)$
\end{tabular}

Values are presented as number (\%).

$\mathrm{CT}$, computed tomography; CNS, central nervous system.
Table 3. Clinical characteristics and univariate analysis according to the result of brain $\mathrm{CT}$

\begin{tabular}{|c|c|c|c|}
\hline \multirow{3}{*}{$\begin{array}{l}\text { Characteristics } \\
\text { Age (yr) }\end{array}$} & \multicolumn{2}{|c|}{ CT findings } & \multirow{3}{*}{$\begin{array}{r}\text { P-value } \\
0.689\end{array}$} \\
\hline & \multicolumn{2}{|c|}{ Positive $(n=146)$ Negative $(n=221)$} & \\
\hline & $65.93 \pm 15.48$ & $66.58 \pm 15.16$ & \\
\hline Male & 79 (54.1) & $116(52.5)$ & 0.761 \\
\hline Current-smoker & $30(20.5)$ & $41(18.6)$ & \\
\hline Frequent alcohol drinking ${ }^{\text {a) }}$ & $18(12.3)$ & $17(7.7)$ & 0.198 \\
\hline GCS & $7.82 \pm 3.31$ & $8.86 \pm 3.17$ & 0.003 \\
\hline Initial GCS $<9$ & $84(57.5)$ & 99 (44.8) & 0.017 \\
\hline Mental status & & & 0.032 \\
\hline Confusion & $0(0)$ & $0(0)$ & \\
\hline Lethargy & 77 (52.8) & $146(66.1)$ & \\
\hline Stupor & $30(20.5)$ & $36(16.3)$ & \\
\hline Semicoma & $18(12.3)$ & $24(10.9)$ & \\
\hline Coma & $21(14.4)$ & $15(6.8)$ & \\
\hline \multicolumn{4}{|l|}{ Underlying conditions } \\
\hline Hypertension & $66(45.2)$ & $100(45.2)$ & 0.924 \\
\hline Diabetes mellitus & $30(20.5)$ & $80(36.1)$ & 0.002 \\
\hline Malignancy & $15(10.3)$ & $30(13.6)$ & 0.002 \\
\hline Chronic liver disease & $6(4.1)$ & $29(13.1)$ & 0.004 \\
\hline Chronic kidney disease & $5(3.4)$ & $21(9.5)$ & 0.029 \\
\hline Cerebrovascular disease & $43(29.5)$ & 49 (22.2) & 0.096 \\
\hline Parkinson's disease & $1(0.7)$ & $7(3.2)$ & 0.115 \\
\hline Dementia & $8(5.5)$ & $34(15.4)$ & 0.004 \\
\hline \multicolumn{4}{|l|}{ Medication } \\
\hline Psychotropic & $7(4.8)$ & $32(14.5)$ & 0.004 \\
\hline Anticonvulsant & $5(3.4)$ & $16(7.2)$ & 0.136 \\
\hline Cardiovascular & $71(48.6)$ & $106(48.0)$ & 0.699 \\
\hline Opioid & $2(1.4)$ & $4(1.8)$ & 0.766 \\
\hline $\begin{array}{l}\text { Medications for chronic } \\
\text { neurologic disorder }\end{array}$ & $6(4.1)$ & $19(8.6)$ & 0.104 \\
\hline \multicolumn{4}{|l|}{ Initial vital sign } \\
\hline $\mathrm{SBP}(\mathrm{mmHg})$ & $117.02 \pm 70.20$ & $108.14 \pm 59.06$ & 0.208 \\
\hline $\mathrm{DBP}(\mathrm{mmHg})$ & $64.90 \pm 37.74$ & $61.58 \pm 32.66$ & 0.385 \\
\hline Heart rate (/min) & $83.40 \pm 23.00$ & $91.83 \pm 24.04$ & 0.003 \\
\hline Respiratory rate (/min) & $16.03 \pm 8.56$ & $17.10 \pm 8.27$ & 0.235 \\
\hline Body temperature $\left({ }^{\circ} \mathrm{C}\right)$ & $36.40 \pm 0.83$ & $36.64 \pm 1.13$ & 0.060 \\
\hline \multicolumn{4}{|l|}{ Lab results } \\
\hline WBC $\left(10^{3} / \mu \mathrm{L}\right)$ & $11.90 \pm 8.82$ & $10.96 \pm 8.17$ & 0.337 \\
\hline Hemoglobin $(\mathrm{g} / \mathrm{dL})$ & $13.30 \pm 2.48$ & $12.41 \pm 2.66$ & 0.607 \\
\hline Sodium (mM/L) & $137.78 \pm 4.38$ & $136.9 \pm 7.12$ & 0.187 \\
\hline Potassium (mM/L) & $3.90 \pm 0.71$ & $4.24 \pm 0.78$ & $<0.001$ \\
\hline BUN (mg/dL) & $22.78 \pm 18.84$ & $28.07 \pm 22.51$ & 0.020 \\
\hline Creatinine $(\mathrm{mg} / \mathrm{dL})$ & $1.24 \pm 1.43$ & $2.19 \pm 9.78$ & 0.248 \\
\hline Glucose (mg/dL) & $169.29 \pm 56.11$ & $178.35 \pm 157.39$ & 0.434 \\
\hline AST (IU/L) & $44.62 \pm 51.64$ & $83.14 \pm 214.88$ & 0.011 \\
\hline ALT (IU/L) & $25.09 \pm 45.21$ & $35.77 \pm 84.57$ & 0.118 \\
\hline Total bilirubin (mg/dL) & $1.23 \pm 1.00$ & $1.64 \pm 2.76$ & 0.047 \\
\hline Albumin $(\mathrm{g} / \mathrm{dL})$ & $4.14 \pm 3.28$ & $3.62 \pm 0.62$ & 0.021 \\
\hline Creatine kinase (U/L) & $296.61 \pm 599.37$ & $389.28 \pm 865.01$ & 0.294 \\
\hline $\mathrm{CRP}(\mathrm{mg} / \mathrm{dL})$ & $1.40 \pm 3.41$ & $4.41 \pm 8.17$ & $<0.001$ \\
\hline C-reactive protein $<2 \mathrm{mg} / \mathrm{dL}$ & 125 (85.6) & $151(68.3)$ & $<0.001$ \\
\hline \multicolumn{4}{|l|}{ Neurologic exam } \\
\hline Focal neurologic deficit & $87(59.6)$ & $3(1.4)$ & $<0.001$ \\
\hline Cranial nerve abnormality & $47(32.2)$ & $2(0.9)$ & $<0.001$ \\
\hline Extremity abnormality & $76(52.1)$ & $2(0.9)$ & $<0.001$ \\
\hline Cerebellar abnormality & $1(0.7)$ & $0(0)$ & 0.398 \\
\hline
\end{tabular}

Values are presented as mean \pm standard deviation or number (\%).

CT, computed tomography; GCS, Glasgow Coma Scale; SBP, systolic blood pressure; DBP, diastolic blood pressure; WBC, white blood cell; BUN, blood urea nitrogen; AST, aspartate aminotransferase; ALT, alanine aminotransferase.

a) $>4$ days per week. 
Table 4. Multivariate analysis results

\begin{tabular}{lccr}
\hline Variable & $\begin{array}{c}\text { Adjusted } \\
\text { odds ratio }\end{array}$ & $\begin{array}{c}\text { 95\% Confidence } \\
\text { interval }\end{array}$ & P-value \\
\hline Focal neurologic deficit & 132.6 & $37.8-464.6$ & $<0.001$ \\
Glasgow Coma Scale $<9$ & 2.4 & $1.2-4.8$ & 0.016 \\
C-reactive protein $<2$ & 3.9 & $1.4-10.6$ & 0.008 \\
\hline
\end{tabular}

In the multivariate analysis, the presence of focal neurologic deficit (OR, 132.6; 95\% Cl, 37.8 to 464.6), C-reactive protein (CRP) of $<2 \mathrm{mg} / \mathrm{dL}(\mathrm{OR}, 3.9 ; 95 \% \mathrm{Cl}, 1.4$ to 10.6$)$, and GCS score of $<9$ $(\mathrm{OR}, 2.4 ; 95 \% \mathrm{Cl}, 1.2$ to 4.8$)$ were significantly associated with positive brain $\mathrm{CT}$ results (Table 4).

To generate the decision tree in the Conditional Inference Tree Analysis, the presence of focal neurologic deficit was the primary predictive factor (96.7\%) of positive CT result. In patients without focal neurologic deficit, 39 (37.5\%) with positive CT scans had GCS scores of $<9$ and CRP levels of $<2 \mathrm{mg} / \mathrm{dL}$. Sixteen patients (11.7\%) showed GCS scores of $\geq 9$, and 4 (11.1\%) had GCS scores of $<9$ and CRP levels of $\geq 2 \mathrm{mg} / \mathrm{dL}$. The accuracy of the decision tree was 0.8311 (95\% Cl, 0.7887 to $0.868 ; \mathrm{P}<0.001)$ (Fig. 1).

\section{DISCUSSION}

Acute AMS caused by intracranial pathology usually requires immediate diagnosis and intervention. Brain CT is regarded as one of the essential approaches to manage AMS. ${ }^{4}$ With technical advancements over the past decade, utilization of brain $\mathrm{CT}$ in the ED has continuously increased. ${ }^{9}$ However, increased rates of CT use can expose patients to excessive levels of radiation and society to higher medical costs. One retrospective study that reviewed brain CT utilization in a single ED found that the rate of brain CT use had increased by 60\% over a 7-year period; however, the diagnostic yield for intracranial hemorrhage had remained constant at approximately $3 \% .^{10}$

Therefore, several guidelines for brain CT have been developed, but are mostly relevant to traumatic brain injuries. ${ }^{11-13}$ Moreover, studies on patients with AMS using brain CT were limited. Hardy and Brennan ${ }^{2}$ evaluated the brain CT of elderly patients (aged $>70$ years) with acute confusion, noting that positive findings were detected in only $14 \%$. Partel et al. ${ }^{6}$ evaluated the brain CT data of poisoned patients with AMS, determining that no cases had abnormal CT findings and that brain CT was performed at a higher rate for these patients nonetheless.

Leong et al. ${ }^{5}$ evaluated 382 brain CT scans performed on patients with AMS over the course of 11 months at a single ED. They reported that diastolic blood pressure of $>80 \mathrm{mmHg}$, GCS score of $<15$, focal weakness, increasing plantar response, dilated pu-

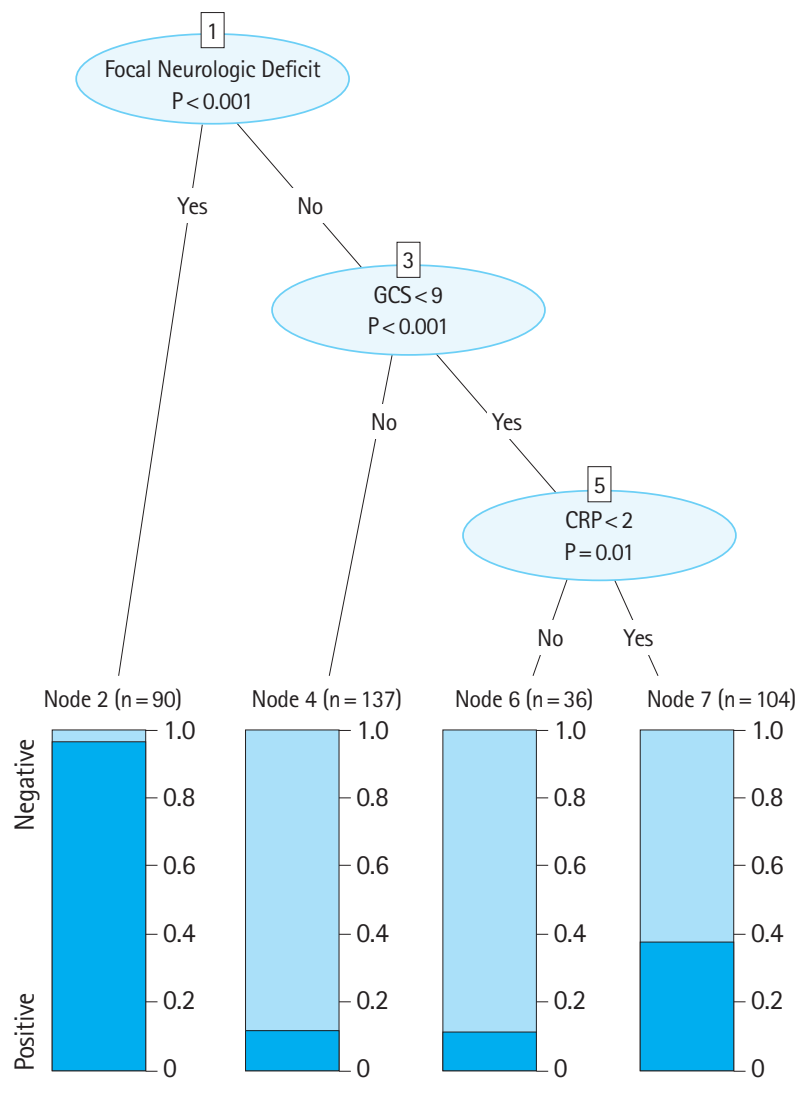

Fig. 1. Conditional inference tree for positive computed tomography (CT) findings. A total of 90 patients had focal neurologic deficit, among whom 87 (96.7\%) had positive CT findings (node 2). One hundred and four patients had Glasgow Coma Scale (GCS) scores of $<9$ and C-reactive protein (CRP) levels of $<2 \mathrm{mg} / \mathrm{dL}$; among them, 39 (37.5\%) had positive CT findings (node 7). One hundred and thirty-seven patients had GCS scores of $\geq 9$; among them, $16(11.7 \%)$ had positive CT findings (node 4). Among the 36 patients with GCS scores of $<9$ and CRP levels of $\geq 2 \mathrm{mg} / \mathrm{dL}, 4(11.1 \%)$ had positive CT findings (node 6 ).

pils, and use of antiplatelet and anticoagulant medications were factors associated with abnormal CT findings. In the present study, the following patient characteristics differed: first, the GCS scores in all patients were $<15$, and second, trauma patients were excluded. Furthermore, we evaluated laboratory test results that are crucially important for differential diagnosis in the ED, which were not included by Leong et al..$^{5}$

In our analysis, the presence of focal neurologic deficit was a significant factor suggesting positive brain CT findings (Table 4 and Fig. 1). Only three (3.3\%) patients with focal neurologic deficit had negative $\mathrm{CT}$ findings: two had an acute ischemic lesion on brain magnetic resonance imaging and one hypotension-caused AMS. Only one patient had cerebellar dysfunction, who needed a cerebellar function test requiring cooperation that is typically not possible in patients with AMS, which might affect the results. 
Furthermore, changes in the mental status are relatively infrequent in patients with posterior circulation stroke. ${ }^{14}$

Based on our results, initial GCS scores of $<9$ and CRP levels of $<2 \mathrm{mg} / \mathrm{dL}$ were also correlated with positive brain CT findings (Table 4 and Fig. 1). Traditionally, brain imaging studies have been recommended for patients with low GCS scores, a protocol supported by our results. ${ }^{4,11,15}$ Neurologic evaluation findings in patients with lower GCS scores $(<9)$ might be more limited and less accurate than those in patients with higher GCS scores, simply due to poor cooperation. ${ }^{3}$ Neurologic evaluation may be easier and more accurate in patients with higher GCS scores.

CRP is a pentraxin released by the liver during the phase response of acute inflammatory reaction. Although every inflammatory condition can increase the CRP level, its high elevation is thought to be suggestive of infection. Patients with severe sepsis and septic shock had higher CRP levels than those with noninfectious systemic inflammatory response syndrome. ${ }^{16}$ In our study, lower CRP levels ( $<2 \mathrm{mg} / \mathrm{dL}$ ) were associated with positive CT results (Table 3 and Fig. 1). Most patients with positive CT results (93.2\%) have CNS pathology (cerebrovascular, CNS infection, CNS tumor, seizure/postictal confusion, and other CNS pathologies) (Table 2). CRP level can be also elevated in many CNS pathologies, such as ischemic stroke and brain hemorrhage. However, in these conditions, increased CRP levels occur several hours after the brain injury; therefore, routine evaluation of CPR levels is not recommended as an initial assessment, and these can affect our results. ${ }^{17,18}$

Based on the Conditional Inference Tree Analysis results, we suggest the following protocol: if the patient has focal neurologic deficit, brain CT should be performed (CT positivity rate, 96.7\%); if the patient has no focal neurologic deficit and if the initial GCS score is $<9$ and CRP is $<2 \mathrm{mg} / \mathrm{dL}$, brain CT can be helpful (CT positivity rate, $37.5 \%$ ); and if GCS score is $\geq 9$ or $<9$ and CRP $\geq 2$ $\mathrm{mg} / \mathrm{dL}$, brain CT might not be helpful (CT positivity rate, $11.7 \%$ and $11.1 \%$, respectively) (Fig. 1). For the generalization of these results, an external validation study should be conducted.

More than $70 \%$ of patients included in the present study underwent brain $\mathrm{CT}$, which is higher compared to relevant previous reports. This could have been influenced by the facts that cases of alcohol ingestion or of AMS in previously neurologically impaired patients were excluded from our study. The rate of positive findings on brain CT was $39.8 \%$, which is not much lower than that of the previous studies $(14 \%, 45 \%)$. ${ }^{2,5}$ Regional and cultural factors, which should be noted here, can also affect the pattern of brain CT utilization.

The present study has several limitations. First, its design is retrospective. Patients without brain CT were excluded from the anal- ysis, although if they had been included and had undergone brain $\mathrm{CT}$, abnormal lesions might have also been found, which could have affected the results. The neurologic status of these patients changes easily, even in those with only minor medical conditions. ${ }^{1,3}$ Moreover, in the retrospective setting, degrees of AMS are often difficult to understand, and, therefore, evaluate. Finally, the study lacks an ordering protocol for brain CT; instead, CT scans were conducted based on the attending physician's decision, which could have resulted in a selection bias. Large-scale prospective multicenter studies will overcome these limitations.

In conclusion, positive findings were detected in 39.8\% of patients with acute AMS who underwent brain CT in the ED. Initial GCS scores of $<9$, CRP levels of $<2 \mathrm{mg} / \mathrm{dL}$, and presence of focal neurologic deficit were significantly associated with positive brain CT findings.

\section{CONFLICT OF INTEREST}

No potential conflict of interest relevant to this article was reported.

\section{ACKNOWLEDGMENTS}

This study is supported by a grant from the SNU EM Research Grant.

\section{REFERENCES}

1. Han JH, Wilber ST. Altered mental status in older patients in the emergency department. Clin Geriatr Med 2013;29:10136.

2. Hardy JE, Brennan N. Computerized tomography of the brain for elderly patients presenting to the emergency department with acute confusion. Emerg Med Australas 2008;20:420-4.

3. Kanich W, Brady WJ, Huff JS, et al. Altered mental status: evaluation and etiology in the ED. Am J Emerg Med 2002;20:613-7.

4. American College of Emergency Physicians. Clinical policy for the initial approach to patients presenting with altered mental status. Ann Emerg Med 1999;33:251-81.

5. Leong LB, Wei Jian $K H$, Vasu $A$, Seow E. Identifying risk factors for an abnormal computed tomographic scan of the head among patients with altered mental status in the emergency department. Eur J Emerg Med 2010;17:219-23.

6. Patel MM, Tsutaoka BT, Banerji S, Blanc PD, Olson KR. ED utilization of computed tomography in a poisoned population. Am J Emerg Med 2002;20:212-7.

7. Hothorn T, Hornik K, Zeileis A. Unbiased recursive partitioning: 
a conditional inference framework. J Comput Graph Stat 2006; 15:651-74.

8. Strobl C, Malley J, Tutz G. An introduction to recursive partitioning: rationale, application, and characteristics of classification and regression trees, bagging, and random forests. Psychol Methods 2009;14:323-48.

9. Lee J, Kirschner J, Pawa S, Wiener DE, Newman DH, Shah K. Computed tomography use in the adult emergency department of an academic urban hospital from 2001 to 2007. Ann Emerg Med 2010;56:591-6.

10. Lee J, Evans CS, Singh N, et al. Head computed tomography utilization and intracranial hemorrhage rates. Emerg Radiol 2013;20:219-23.

11. Haydel MJ, Preston CA, Mills TJ, Luber S, Blaudeau E, DeBlieux PM. Indications for computed tomography in patients with minor head injury. N Engl J Med 2000;343:100-5.

12. Stiell IG, Clement CM, Rowe BH, et al. Comparison of the Canadian CT Head Rule and the New Orleans Criteria in patients with minor head injury. JAMA 2005;294:1511-8.

13. Papa L, Stiell IG, Clement CM, et al. Performance of the Canadian CT Head Rule and the New Orleans Criteria for predict- ing any traumatic intracranial injury on computed tomography in a United States Level I trauma center. Acad Emerg Med 2012;19:2-10.

14. Nouh A, Remke J, Ruland S. Ischemic posterior circulation stroke: a review of anatomy, clinical presentations, diagnosis, and current management. Front Neurol 2014;5:30.

15. Stiell IG, Wells GA, Vandemheen K, et al. The Canadian CT Head Rule for patients with minor head injury. Lancet 2001;357: 1391-6.

16. Sierra R, Rello J, Bailen MA, et al. C-reactive protein used as an early indicator of infection in patients with systemic inflammatory response syndrome. Intensive Care Med 2004;30:203845.

17. Di Napoli M, Godoy DA, Campi V, et al. C-reactive protein in intracerebral hemorrhage: time course, tissue localization, and prognosis. Neurology 2012;79:690-9.

18. Di Napoli M, Schwaninger M, Cappelli R, et al. Evaluation of C-reactive protein measurement for assessing the risk and prognosis in ischemic stroke: a statement for health care professionals from the CRP Pooling Project members. Stroke 2005; 36:1316-29. 